Ensino, Saúde e Ambiente -VV5 (1), pp. 63-82, abril. 2012

\title{
REPRESENTAÇÃO SOCIAL DE CIÊNCIA: UM ESTUDO PRELIMINAR NAS SÉRIES INICIAIS DO ENSINO FUNDAMENTAL
}

\section{SOCIAL REPRESENTATION OF SCIENCE: A PRELIMINARY STUDY IN THE FIRST YEARS OF ELEMENTARY SCHOOL}

\author{
Claudia Maria Barth Petter ${ }^{1}$ e Marco Antonio Moreira ${ }^{2}$ \\ ${ }^{1}$ Escola Estadual de Ensino Fundamental Moinhos Estrela, RS, Brasil \\ claudiapetter@gmail.com \\ ${ }^{2}$ Instituto de Física - UFRGS - Porto Alegre, RS, Brasil \\ moreira@if.ufrgs.br
}

\begin{abstract}
RESUMO
O propósito desta pesquisa foi averiguar a Representação Social de Ciência entre alunos, pais e professores nas Séries Iniciais do Ensino Fundamental de uma Escola Estadual, na Região Sul do Brasil, além de analisar os conteúdos de cada série, a maneira como eram trabalhados em sala de aula, se a bagagem de cada indivíduo era ou não contemplada, e a possível influência da escola nesta construção. Para a realização do trabalho, fez-se necessário aprofundar os conceitos de ancoragem e objetivação da Representação Social para tentar identificar o núcleo central e a região periférica. Na fundamentação da pesquisa, utilizou-se a Epistemologia de Lakatos, que faz referência ao núcleo rígido e ao cinturão protetor. As teorias de aprendizagem envolvidas se referem a Piaget, Vigotsky e Ausubel, explícitas ao longo deste trabalho. A metodologia utilizada constituiu-se de uma abordagem plurimetodológica, favorecida pela Teoria das Representações Sociais. A análise feita permitiu a identificação de uma parte desse processo de construção que demonstra as categorias estabelecidas e seus sentidos. É possível supor que a Representação Social de Ciência desta pesquisa está vinculada ao estudo, conhecimento e descoberta, que valorizam a qualidade de vida das pessoas.
\end{abstract}

Palavras-chaves: Ciência, Representação Social, séries iniciais.

\begin{abstract}
This research aimed at investigating the Social Representation of Science among initial grades students, parents and teachers of a Southern Brazilian State Public School. Besides this, it aimed at analyzing the contents of each grade, the way these contents were approached in class and whether knowledge of each individual was used or not in the classroom daily life and if school had any influence on this construction. It was necessary to deepen the knowledge of the concepts of anchorage and objectification of the Social Representation in order to detect the central nucleus and the peripheral region of it. Lakatos's Epistemology, which makes reference to the rigid nucleus and the protective belt, was used to validate the research. The learning theories involved in this study were those of Piaget, Vigotsky and Ausubel, and are made explicit along this work. The methodology used had a multi-methodological approach supported by the Social Representations Theory. The analysis carried out allowed to identify part of this construction process that shows the established categories and their meanings. It is possible to suppose that the Social Representation of Science of this research is linked to study, knowledge and discovery, which value people's quality of life.
\end{abstract}

Key-words: Science, Social Representation, elementary school. 


\section{INTRODUÇÃO}

Perrenoud (2000) afirma que é necessário unir saber e experiências para dar significado àquilo que é aprendido na escola. Logo, o professor necessita pesquisar a partir de suas práticas pedagógicas. Como desenvolver as aulas de modo que os alunos possam construir ou reconstruir seus conhecimentos? Como agir para que os educandos consigam desenvolver habilidades e competências que servirão para a sua vida fora do ambiente escolar? Aqui, entra a investigação no ensino, ou seja, o professor como investigador de suas práticas educativas. Nesse sentido, a presente pesquisa buscou saber concepções de Ciência para alunos, pais e professoras com a intenção de averiguar a possível Representação Social que existe nestes grupos e como estes dados influenciam ou não na implementação do Ensino de Ciências no ambiente escolar.

Apresentamos, a seguir, algumas reflexões sobre o Ensino de Ciências na atualidade. Em seguida, fazemos referência à fundamentação teórica relativa às Representações Sociais, bem como às teorias de aprendizagem envolvidas na pesquisa. Por fim, descrevemos, a metodologia utilizada neste estudo e as possibilidades encontradas para dar prosseguimento ao trabalho.

\section{O ENSINO DE CIÊNCIAS}

Qual a finalidade da Ciência? Quais os fins da Educação? A quem a Ciência tem servido atualmente? Para quem temos educado os nossos alunos? São questões que, segundo Santos e Schnetzler (1997), devem estar presentes no fazer pedagógico de todo educador.

Na visão de Fracalanza et al. (1986, p.101),

"o ensino de Ciências representava uma tendência pedagógica hoje comumente denominada transmissão cultural, em virtude de ter como finalidade principal transmitir ao aluno o grande patrimônio de conhecimentos construídos pela nossa civilização". Ideia que dominou o pensamento de docentes por muito tempo e que, "no caso do ensino de ciências, [...] objetivava levar ao aluno pura $e$ simplesmente o produto final da atividade científica, ou seja, o conhecimento já pronto e organizado, com aura de verdade acabada. [...] A metodologia de ensino era diretiva, centrada no professor, baseada principalmente em exposições (orais elou visuais) $e$ demonstrações, visando assegurar fundamentalmente a memorização da informação por parte do aluno (Idem)”.

Para que uma mudança se concretizasse, desencadearam-se reformulações no sistema educacional como um todo, assim como na estrutura curricular e nos princípios metodológicos nas mais diversas áreas. No caso específico do Ensino de Ciências, as discussões e os estudos apontaram para a necessidade de se praticar um ensino mais vivo e, consequentemente, mais dinâmico, pautado numa concepção de Ciência como atividade humana que vença o desafio de "pôr o saber científico ao alcance de um público escolar em escala sem precedentes” (Delizoicov, 2002, p. 33). 
No entanto, o ensino, por constituir o elemento responsável pela socialização do conhecimento científico, acaba reproduzindo uma concepção de Ciência, onde esse conhecimento é apresentado como superior, inquestionável, neutro, objetivo, imparcial e universal. Tal visão fortalece o ideário ciência/cientista, mantendo-os como inacessíveis e, consequentemente, inquestionáveis, consolidando a ideia da população em geral como mera consumidora da ciência e tecnologia, produzidas pelos cientistas para melhorar a qualidade de vida das pessoas. Todavia, como já foi mencionado anteriormente, este perfil de Ciência não corresponde à realidade (Delizoicov, 2002).

Ao analisar a questão da experimentação na escola, Weissmann (1998) afirma que o espaço físico da mesma é a expressão de seu projeto pedagógico e, desta forma, a existência ou ausência de um laboratório, dentro ou fora da sala de aula, do tipo de mobiliário e equipamento, fala não só da importância dada às ciências dentro do currículo escolar, mas também da abordagem didática que lhe é dada. Neste sentido, a autora propõe que, nos dias de hoje, a sala de aula deve ser transformada em laboratório e que as abordagens atuais do Ensino de Ciências e a variedade de atividades propostas requerem diferentes espaços de experimentação: laboratório multifuncional (flexibilidade para as várias ciências), espaços para material vivo, horta, centro de documentação, entre outros.

Por outro lado, partindo do princípio básico de que a participação e o envolvimento do aluno no processo são relevantes, assim como a percepção do professor no processo coletivo da construção do ensino e da aprendizagem, Carvalho \& Gil-Pérez (2004, pp.42-43) demonstram a importância da relação professor-aluno para o programa de atividades conjuntas:

"Quando se pretende organizar a aprendizagem como uma construção de conhecimentos por parte dos alunos, [...] esta que deve ser colocada funcionalmente, ou seja, como tratamento de situações problemáticas de interesse. [...] O desenvolvimento de um tema pode ser visto agora como o tratamento da problemática proposta, um tratamento que deve inicialmente ser qualitativo - o que constituirá uma excelente ocasião para que os alunos comecem a explicitar funcionalmente suas concepções espontâneas - e conduza à formulação de problemas mais precisos e à construção de hipóteses que focalizem o estudo a realizar".

Ou, ainda, como nos remete Delizoicov (2002, p.153),

"Tornar a aprendizagem dos conhecimentos científicos em sala de aula num desafio prazeroso é conseguir que seja significativa para todos, tanto para o professor quanto para o conjunto dos alunos que compõem a turma. É transformá-la em um projeto coletivo, em que a aventura da busca do novo, do desconhecido, de sua potencialidade, de seus riscos e limites seja a oportunidade para o exercício e o aprendizado das relações sociais e dos valores. Nessa perspectiva, a sala de aula passa a ser espaço de trocas reais entre os alunos e entre eles e o professor, diálogo que é construído entre conhecimentos sobre o mundo onde se vive e que, ao ser um projeto coletivo, estabelece a mediação entre as demandas afetivas $e$ cognitivas de cada um dos participantes". 
O significado que a atividade de Ensino de Ciências terá durante o exercício de sua realização e, consequentemente, no processo de aprendizagem, dependerá, provavelmente, da disponibilidade de professores e alunos da escola em estarem emocionalmente dispostos para o efetivo desenvolvimento das ações praticadas nas atividades desse ensino e nelas embutidas. Delizoicov (ibid.) reforça-nos dizendo que

"a sala de aula passa a ser espaço de trocas reais entre os alunos e entre eles e o professor, diálogo que é construído entre conhecimentos sobre o mundo onde se vive e que, ao ser um projeto coletivo, estabelece a mediação entre as demandas afetivas e cognitivas de cada um dos participantes".

Para Freire (2001: 80-81),

"há uma relação entre a alegria necessária à atividade educativa e a esperança. A esperança de que professor e alunos juntos podem aprender, ensinar, inquietarem-se, produzir e juntos igualmente resistir aos obstáculos à nossa alegria. Seria uma contradição se, inacabado e consciente do inacabamento, primeiro, o ser humano não se inscrevesse ou não se achasse predisposto a participar de um movimento constante de busca e, segundo, se buscasse sem esperança. (...) A esperança é uma espécie de ímpeto natural possível e necessário, a desesperança é o aborto deste ímpeto".

Pretendemos, a partir das possíveis representações sociais que se evidenciarem nesta pesquisa, buscar elementos necessários para uma tentativa de melhoria da qualidade do Ensino de Ciências em sala de aula e, de modo geral, das ações educativas na escola. Para isso, reforçamos, as palavras de Delizoicov (2002: 153), essa intenção:

"Tornar a aprendizagem dos conhecimentos científicos em sala de aula num desafio prazeroso é conseguir que seja significativa para todos, tanto para o professor quanto para o conjunto dos alunos que compõem a turma. É transformá-la em um projeto coletivo, em que a aventura da busca do novo, do desconhecido, de sua potencialidade, de seus riscos e limites seja a oportunidade para o exercício e o aprendizado das relações sociais e dos valores".

\section{REPRESENTAÇÕES SOCIAIS}

As Representações Sociais, segundo definição clássica apresentada por Jodelet (1985), são modalidades de conhecimento prático orientadas para a comunicação e para a compreensão do contexto social, material e ideativo em que vivemos. São, consequentemente, formas de conhecimento que se manifestam como elementos cognitivos - imagens, conceitos, categorias, teorias —, mas que não se reduzem jamais aos componentes cognitivos. Sendo socialmente elaboradas e compartilhadas, contribuem para a construção de uma realidade comum que possibilita a comunicação. Deste modo, as representações são, essencialmente, fenômenos sociais que, mesmo acessados a partir do seu conteúdo cognitivo, têm de ser entendidos a partir do seu contexto de produção. Ou seja, a partir das funções simbólicas e ideológicas a que servem e das formas de comunicação onde circulam. 
É, ainda, uma expressão da realidade intraindividual, uma exteriorização do afeto. Conforme Jodelet (1989a, p.38),

"As representações sociais devem ser estudadas articulando elementos afetivos, mentais, sociais, integrando a cognição, a linguagem e a comunicação às relações sociais que afetam as representações sociais e à realidade material, social e ideativa sobre a qual elas intervêm".

Dois aspectos são particularmente relevantes neste segundo eixo do campo de estudos das Representações Sociais. Em primeiro lugar, o posicionamento sobre a relação indivíduo-sociedade, que foge tanto ao determinismo social — onde o homem é produto da sociedade - quanto ao voluntarismo puro, que vê o sujeito como livre agente. Busca um posicionamento mais integrador que, embora situando o homem no processo histórico, abre lugar para as forças criativas da subjetividade. Em segundo lugar, ao abrir espaço para a subjetividade, traz para o centro da discussão a questão do afeto: as representações não são, assim, meras expressões cognitivas; são permeadas, também, pelo afeto.

Nos diversos textos que lidam com as Representações Sociais, enquanto formas de conhecimento prático, são destacadas diversas funções, entre elas: orientação das condutas e das comunicações (função social); proteção e legitimação de identidades sociais (função afetiva) e familiarização com a novidade (função cognitiva).

A função cognitiva de familiarização com a novidade, ao transformar o estranho — potencialmente ameaçador — em algo familiar, permite-nos evidenciar os dois principais processos envolvidos na elaboração das representações postulados por Moscovici em 1961: ancoragem e objetivação. A ancoragem refere-se à inserção orgânica do que é estranho no pensamento já constituído, ou seja, ancoramos o desconhecido em representações já existentes. Moscovici (1978, p.88) a concebe como um processo de domesticação da novidade sob a pressão dos valores do grupo, transformando-a em um saber capaz de influenciar, pois "nos limites em que ela penetrou numa camada social, também se constitui aí num meio capaz de influenciar os outros e, sob esse aspecto, adquire status instrumental". Em suma, a ancoragem é feita na realidade social vivida, não sendo, portanto, concebida como processo cognitivo intraindividual.

A cristalização de uma representação nos remete, por sua vez, ao segundo processo: a objetivação, que é essencialmente uma operação formadora de imagens, o processo através do qual noções abstratas são transformadas em algo concreto, quase tangível, tornando-se "tão vívidos que seu conteúdo interno assume o caráter de uma realidade externa" (Moscovici, 1988, p.92). Este processo implica três etapas: primeiramente, a descontextualização da informação através de critérios normativos e culturais; em segundo lugar, a formação de um núcleo figurativo, a formação de uma estrutura que reproduz de maneira figurativa uma estrutura conceitual; e, finalmente, a naturalização, ou seja, a transformação destas imagens em elementos da realidade.

As múltiplas dimensões do campo de estudos das Representações Sociais, a interdisciplinaridade que lhe é intrínseca, as contradições e paradoxos com que se depara o pesquisador e as inúmeras dualidades (campo estruturado/núcleo estruturante; conteúdo/processo; contexto histórico/ "aqui-e-agora"), que, a exemplo das unidades subatômicas estudadas pela Física Quântica, têm um aspecto dual; apresentando-se ora 
como partículas, ora como ondas, situam as representações sociais no seio do debate mais atual sobre a Ciência, não só pelo questionamento que suscita sobre a natureza do conhecimento e sobre a relação indivíduo-sociedade, mas, sobretudo, por inseri-la dentro do paradigma da complexidade (Morin, 1983).

Não se trata de buscar uma síntese, mas, conforme Morin (1984, p.35),

"O que me interessa não é uma síntese, mas um pensamento transdisciplinar, um pensamento que não se quebre nas fronteiras entre as disciplinas. $O$ que me interessa é o fenômeno multidimensional, e não a disciplina que recorta uma dimensão nesse fenômeno. Tudo o que é humano é ao mesmo tempo psíquico, sociológico, econômico, histórico, demográfico. É importante que estes aspectos não sejam separados, mas sim que concorram para uma visão poliocular. $O$ que me estimula é a preocupação de ocultar o menos possível a complexidade do real".

A concepção construtivista defende que, em um processo de aprendizagem, sejam considerados aspectos globais, como a disposição dos alunos para esta aprendizagem, os instrumentos, as habilidades, as estratégias que são capazes de utilizar e, principalmente, os conhecimentos prévios que possuem sobre o assunto a ser ensinado. Tais conhecimentos englobam não só aqueles sobre o próprio conceito, como também relações diretas ou indiretas que o aluno é capaz de estabelecer com o novo conteúdo. Desta forma, segundo essa concepção, uma aprendizagem será significativa quando o aluno for capaz de estabelecer relações coerentes entre o que já sabe e o novo conhecimento que lhe está sendo apresentado.

\section{FUNDAMENTAÇÃO EPISTEMOLÓGICA}

Neste estudo, utilizamos como referencial epistemológico a Filosofia da Ciência de Imre Lakatos, da qual apresentamos os conceitos centrais, núcleo rígido e cinturão protetor, por estarem muito relacionados à Teoria das Representações Sociais.

O núcleo rígido (hardcore) de um programa é aquilo que essencialmente o identifica e caracteriza, constituindo-se de uma ou mais hipóteses teóricas. Por "uma decisão metodológica de seus protagonistas" (Lakatos 1970, p. 133), o núcleo rígido de um programa de pesquisa é "decretado" não-refutável. Possíveis discrepâncias com os resultados empíricos são eliminadas pela modificação das hipóteses do cinturão protetor. Essa regra é a heurística negativa do programa e tem a função de limitar, metodologicamente, a incerteza quanto à parte da teoria atingida pelas "falseações". Recomenda-se direcionar as "refutações" para as hipóteses não-essenciais da teoria. A heurística negativa representa uma regra de tolerância, que visa a dar uma chance para os princípios fundamentais a fim de o núcleo mostrar a sua potencialidade.

Deixemos a Lakatos a palavra (1970, p. 175):

"Minha abordagem implica um novo critério de demarcação entre ciência madura, que consiste de programas de pesquisa, e ciência imatura, que consiste de uma colcha de retalhos de tentativas $e$ erros...". 
"A ciência madura consiste de programas de pesquisa nos quais são antecipados não apenas fatos novos, mas também novas teorias auxiliares; a ciência madura possui 'poder heurístico', em contraste com os processos banais de tentativa e erro. Lembremos que na heurística positiva de um programa vigoroso há, desde o início, um esboço geral de como construir os cinturões protetores: esse poder heurístico gera a autonomia da ciência teórica.

Lakatos mostra que, quando uma teoria está sendo testada empiricamente, ela o está sendo não isoladamente, mas em conjunto com as diversas teorias auxiliares que lhe dão suporte. Ou seja, testes empíricos não testam teorias, mas conjuntos de teorias relacionadas entre si.

Para o referido autor,

"A história da ciência tem sido e deve ser uma história de programas de investigação que competem (ou se prefere de paradigmas), mas não tem sido e nem deve converter-se em uma sucessão de períodos de ciência normal; quanto antes começa a competência tanto melhor para o progresso" (Lakatos, 1993, p. 92).

O progresso da Ciência se fundamenta no suposto de que não há incomensurabilidade entre teorias e, por conseguinte, confia-se na possibilidade de diálogo entre programas de investigação, sustentado em certas regras gerais de lógica formal e de acordos da comunidade científica.

\section{TEORIAS DE APRENDIZAGEM}

No presente estudo, foram usadas ideias centrais das teorias de aprendizagem de Piaget, Vigotsky e Ausubel por estarem interligadas com a Teoria das Representações Sociais neste estudo.

Para Piaget (1979), cada aluno está num nível de amadurecimento e o processo de aprendizagem ocorre a partir de uma desequilibração cognitiva, isto é, um ser humano aprende no momento em que se depara com um problema. Neste momento, sua estrutura cognitiva, que antes estava em equilíbrio, passa por um momento de desequilíbrio, do qual, para sair, é preciso encontrar uma solução para o problema. Este processo leva não somente a uma assimilação, mas também a uma internalização do conhecimento adquirido, ou seja, à construção do conhecimento pelo indivíduo.

$\mathrm{Na}$ teoria psicogenética, o erro deixa de ser uma falha do aluno e passa a ser componente do processo educacional, tornando-se uma das maiores ferramentas do professor para entender o pensamento do discente e tentar ajudá-lo a compreender melhor um dado conteúdo. $\mathrm{O}$ fato de um educando errar, continua significando dificuldade em compreender um conteúdo, mas as razões que o levaram a esse erro ganham uma nova importância e é necessário investigá-las para que ele possa superar os obstáculos. Portanto, a avaliação contínua é fundamental para acompanhar o educando e aperfeiçoar o processo de aprendizagem. 
Para Vygotsky (1991), a função do professor é a de orientar de forma ativa e servir de guia para o aluno de modo a oferecer apoio cognitivo. $\mathrm{O}$ docente deve ser capaz de ajudá-lo a entender um determinado assunto e, ao mesmo tempo, relacioná-lo ao conteúdo com experiências pessoais e ao contexto no qual o conhecimento está sendo aplicado. Ele deve também interferir na zona de desenvolvimento proximal de cada educando sempre que não ocorrerem avanços espontâneos por parte deste. As várias atividades oferecidas devem ser flexíveis, permitindo ajustes no plano de aula. A intervenção, por parte do professor, é fundamental para o desenvolvimento do aluno. Uma forma de colocá-la em prática é questionar as respostas dos discentes para observar como a interferência de outro sujeito atinge o seu desenvolvimento e examinar não apenas os resultados do desempenho do aprendiz, mas também os processos psicológicos em transformação.

Para Ausubel (1978), avaliar o que o aprendiz já sabe em um campo conceitual não é uma tarefa fácil; a proposta é que sejam identificados os conceitos (subsunçores) relevantes que ele possui e que se avalie até que ponto eles se encontram diferenciados na estrutura cognitiva. É importante ressaltar que a introdução de conceitos deve ser sempre potencialmente significativa; a aprendizagem realizada de forma receptiva não significa abstração passiva. O momento de aquisição deve ser ativo e quanto mais o for este processo, mais significativos e úteis serão os conceitos.

Segundo a abordagem ausubeliana, o professor desempenha um papel importante e tem como principais funções:

- organizar o conteúdo a ser ensinado, partindo do todo (visão geral) para chegar aos conteúdos específicos;

- identificar quais os subsunçores (conhecimento prévio) que o aluno deve ter para que possa aprender o conteúdo significativamente;

- verificar o que o aluno sabe sobre o conteúdo a ser ministrado e, caso lhe faltem subsunçores, de uma forma ou outra, levá-lo a adquiri-los.

As três teorias de aprendizagem apresentadas, de forma sucinta, nos fazem refletir e repensar o Ensino de Ciências para alunos das Séries Iniciais do Ensino Fundamental, o que é necessário para evoluir e melhorar a aprendizagem nas escolas. Portanto, entender a teoria para partir à prática, o contato com os alunos, pais e professoras serão os temas abordados na pesquisa, a fim de perceber a importância deste estudo, visando, assim, contribuir para a melhoria da qualidade do Ensino de Ciências.

\section{METODOLOGIA DA PESQUISA}

As pesquisas em Representações Sociais, como esta, buscam produzir um outro tipo de conhecimento acerca dos fenômenos de representação, os quais Moscovici chamou de universos consensuais de pensamento.

Esse processo de transformação, representado pela construção do objeto de pesquisa, é considerado por Sá (1998, p.23), como sendo "um processo pelo qual o fenômeno de representação social é simplificado e tornado compreensível pela teoria, para a finalidade da pesquisa". O campo de estudos das representações sociais está, desde as suas origens, associado ao interesse básico sobre as relações entre o pensamento erudito (ciência) e o pensamento popular (representação social). 
Optamos por realizar uma pesquisa descritiva, caracterizada por Rampazzo (2002, p. 54) da seguinte forma: "A pesquisa descritiva observa, registra, analisa $e$ correlaciona fatos e fenômenos do mundo físico e, especialmente, do mundo humano sem a interferência do pesquisador". Logo, considerando pertinente a escolha, uma vez que, além das características mencionadas, a mesma possibilita a busca do conhecimento de situações e relações que ocorrem na vida social (ibid.), caso das representações sociais.

Dentre as diversas formas que uma pesquisa descritiva pode assumir, nos decidimos pelo estudo de caso, "pesquisa sobre um determinado indivíduo, família, grupo ou comunidade para examinar aspectos variados de sua vida" (op.cit., p.55). Acreditamos que a escolha nos possibilitaria abordar com maior profundidade as questões, uma vez que estivemos trabalhando com uma pequena parcela dos sujeitos que compõem a população de estudantes, pais e professoras da Rede Estadual de Ensino.

Conforme Sá (1996, p. 99),

"a pesquisa das representações sociais tem se caracterizado, desde o início, por uma utilização bastante criativa e diversificada de métodos e pelo desenvolvimento contínuo de novas técnicas, tanto no que se refere à coleta quanto ao tratamento dos dados".

Todavia, a opção implica pesquisar seus três componentes essenciais: conteúdo, estrutura interna e núcleo central, o que envolve, por sua vez, uma abordagem plurimetodológica.

\section{Contexto}

A presente pesquisa foi realizada em uma Escola Estadual de Ensino Fundamental, localizada em um bairro da periferia do município de Estrela, RS, Brasil e atende um público de 260(duzentos e sessenta) alunos nos turnos manhã e tarde.

\section{Amostras}

O estudo envolveu as quatro turmas das Séries Iniciais do Ensino Fundamental, ou seja, $1^{\mathrm{a}}$ série, $2^{\mathrm{a}}$ série, $3^{\mathrm{a}}$ série e $4^{\mathrm{a}}$ série, num total de $100(\mathrm{cem})$ alunos. Também participaram as 4 ( quatro) professoras que trabalhavam com as referidas turmas e 20 ( vinte) pais escolhidos aleatoriamente.

\section{Instrumento e registro de coleta de dados}

Os registros da pesquisa foram feitos nos meses de março, abril e maio de 2009. Ao iniciar o estudo, foi proposta aos alunos a seguinte pergunta: $O$ que é Ciência para você? A construção oral da mesma deu-se através do diálogo e, durante a discussão, procurou-se, sempre que possível, questioná-los até levá-los à escrita. Posteriormente, pediu-se que apontassem as palavras mais importantes na sua definição de Ciência. Por estar a pergunta diretamente relacionada à identificação do núcleo central, justificou-se a utilização da técnica da associação ou evocação livre, considerada por Sá "de relevância da teoria do núcleo central "(1996 p. 115). 
No final do mês de maio, foi solicitado aos discentes que, através de um desenho, mostrassem o que Ciência representava para eles e justificassem a explicação referente à ilustração, o que apoia Abric (2001): permitir que o sujeito possa expressar de forma ainda mais espontânea sua ideia através de desenhos. Já aos pais, foi utilizado o método interrogativo que consiste em obter uma expressão verbal do sujeito sobre o objeto de representação em estudo, assim como o primeiro instrumento de coleta de dados utilizado com os alunos.

Quanto às professoras, foi utilizado um questionário em que, inicialmente, foram coletados dados sobre a formação e o tempo de serviço no magistério. Em seguida, foram solicitadas a listar seis palavras que lhes viessem à mente ao ouvirem a palavra Ciência, ressaltando-se que as mesmas deveriam ser hierarquizadas de acordo com a importância de cada uma. Destas, cada educadora deveria escolher as três que, na sua concepção, melhor definissem Ciência e escrever o significado das mesmas, o que possibilitou às entrevistadas uma análise da sua produção, atendendo-se, assim, o princípio de se fazer com que o sujeito efetue sobre sua própria produção um trabalho cognitivo de análise. (Sá, 1998).

\section{ANÁLISE E RESULTADOS}

Os registros realizados foram trabalhados através da utilização de duas técnicas de análise que variaram em função do tipo de material a ser examinado. Dessa forma, aplicou-se a técnica da análise do conteúdo (Bardin, 1979) para o questionário feito com as professoras; enquanto que para a análise das evocações livres, foi escolhido o método Vérges (Sá, 1996) nos instrumentos coletados com alunos, pais e professoras.

Por conseguinte, o fato da análise de conteúdo apresentar essa propriedade análise quantitativa e qualitativa que possibilita inferir conhecimentos que dizem respeito ao processo de produção e/ou recepção das comunicações -, justifica a opção por essa técnica, o que permitiu alcançar os objetivos a que se propôs este trabalho.

A análise de conteúdo deve abranger basicamente três fases: pré-análise, exploração do material, tratamento dos resultados obtidos e interpretação (Minayo, 1994). A análise das evocações livres pelo método de Vergés (Sá, 1996) busca identificar o núcleo central das representações sociais de Ciência através da determinação da frequência da ordem das palavras evocadas, isto é, aquelas que são centrais de onde emanam as demais evocações consideradas periféricas pelo posicionamento hierárquico na média de frequência das evocações (Nascimento, 2002).

\section{Em busca das Representações Sociais}

Após ter discutido, nas seções anteriores, os aspectos teóricos metodológicos que fundamentaram o presente estudo, estaremos, nesta seção, apresentando os resultados da análise dos registros feitos durante a pesquisa. Através das diferentes técnicas empregadas, buscamos identificar uma possível Representação Social de Ciência que os alunos, pais e professoras apresentaram à luz das teorias que nortearam este trabalho. 
a) O conteúdo das Representações Sociais de Ciência dos estudantes.

Buscando identificar os conteúdos da representação social de Ciência entre os estudantes, realizou-se a análise das respostas dadas à questão: $O$ que é Ciência para você?

Essa análise inicial revelou uma diversidade de temas que foram organizados em expressões que pareciam revelar as idéias por eles manifestadas, totalizando um número de 27 (vinte e sete) diferentes respostas, representadas na Tabela 1. Nesta tabela constam resultados apresentados pelos alunos através da associação livre.

Tabela 1 - Expressões relacionadas à Ciência e suas respectivas frequências para os cem alunos envolvidos na pesquisa.

\begin{tabular}{|l|l|l|}
\hline$N^{\mathbf{o}}$ & Expressão & Frequência \\
\hline 01 & Descoberta & 10 \\
\hline 02 & Natureza & 08 \\
\hline 03 & Estudo & 08 \\
\hline 04 & Plantas & 08 \\
\hline 05 & Corpo humano & 07 \\
\hline 06 & Pesquisa & 06 \\
\hline 07 & Laboratório & 06 \\
\hline 08 & Serve para usar (televisão) & 06 \\
\hline 09 & Invenção & 05 \\
\hline 10 & Curar doenças & 05 \\
\hline 11 & Planetas & 05 \\
\hline 12 & Cura de certas doenças & 05 \\
\hline 13 & Inventos & 04 \\
\hline 14 & Experiência & 04 \\
\hline 15 & Meio ambiente & 04 \\
\hline 16 & Estudo fauna e doenças & 03 \\
\hline 17 & Não sei & 03 \\
\hline 18 & Saber cuidar dos filhos & 02 \\
\hline 19 & Todos tipos de coisas & 02 \\
\hline 20 & Coisas que fazemos & 02 \\
\hline 21 & Salvar vidas & 02 \\
\hline 22 & Tratamento & 01 \\
\hline 23 & Vou aprender na 6 ${ }^{\text {série }}$ & 01 \\
\hline 24 & É legal & 01 \\
\hline 25 & Cura do câncer & 01 \\
\hline 26 & Binóculo, luneta & 01 \\
\hline 27 & Eclipse & 01 \\
\hline
\end{tabular}

A seguir, aprofundando a leitura e análise dessas 27 expressões informadas, foi possível estabelecer 09 (nove) categorias, as quais foram agrupadas por expressões semelhantes ao que os alunos concebem como Ciência. As nove categorias 
estabelecidas, com suas respectivas frequências absolutas e percentuais, estão representadas na Tabela 2:

Tabela 2 - Distribuição das Categorias e sua freqüências absoluta e percentual

\begin{tabular}{|l|l|l|l|}
\hline $\mathrm{N}^{\mathbf{o}}$ & Expressão & Freqüência & Percentual \\
\hline 01 & Descoberta & 22 & $22 \%$ \\
\hline 02 & Natureza & 19 & $19 \%$ \\
\hline 03 & Invenção & 14 & $14 \%$ \\
\hline 04 & Pesquisa & 14 & $14 \%$ \\
\hline 05 & Estudo & 11 & $11 \%$ \\
\hline 06 & Corpo humano & 07 & $07 \%$ \\
\hline 07 & Planetas & 05 & $05 \%$ \\
\hline 08 & Outros & 05 & $05 \%$ \\
\hline 09 & Não sei & 03 & $03 \%$ \\
\hline
\end{tabular}

A partir dos dados acima mencionados pode-se supor que para os alunos, o núcleo duro da Representação Social sobre Ciência se caracteriza possivelmente pela:

- descoberta: que envolve a cura de doenças, experiências, tratamento;

- natureza: refere-se às plantas, meio ambiente, eclipse;

- invenção: serve para usar, como binóculo, luneta, televisão;

- pesquisa: salvar vidas;

- estudo: corpo humano, estudo dos animais, as doenças, saber cuidar;

Inferiu-se que para os estudantes a descoberta, a pesquisa e o estudo podem aliviar dores e salvar vidas. Enquanto que as invenções servem como instrumentos para serem usados no dia-a-dia.

A partir de seus estudos, Piaget defendia que a reflexão sobre a educação não deveria ser concentrada nos conteúdos, mas em como as crianças operam os dados da realidade, ideia que corrobora a intenção desta pesquisa em averiguar as Representações Sociais sobre Ciências que aqui se estabelece.

Para Piaget a aprendizagem dá-se através da assimilação, da acomodação, da adaptação aliadas ao equilíbrio. Segundo este esquema, o ser humano assimila os dados que obtém do exterior, mas uma vez que já tem uma estrutura mental que não está "vazia", precisa adaptar esses dados à estrutura mental já existente. Uma vez que os dados são adaptados a si, dá-se a acomodação. Para Piaget, o homem é o ser mais adaptável do mundo. Este esquema revela que nenhum conhecimento nos chega do exterior sem que sofra nenhuma alteração pela nossa parte, ou seja, tudo o que aprendemos é influenciado por aquilo que já tinhamos aprendido.

Segundo Moreira (1999), o sujeito constrói esquemas mentais de assimilação para abordar a realidade. Quando o organismo assimila, incorpora a realidade a seus esquemas de ação impondo-se ao meio. Quando os esquemas de assimilação não conseguem assimilar determinada situação, o organismo (mente) desiste ou se modifica. No caso de modificação, ocorre a acomodação, ou seja, uma reestruturação da estrutura cognitiva (esquemas de assimilação existentes) que resulta em novos esquemas de assimilação. É através da acomodação que se dá o desenvolvimento cognitivo. 
Experiências acomodadas dão origem a novos esquemas de assimilação, alcançando-se um novo estado de equilíbrio. A mente sendo

uma estrutura (cognitiva) tende a funcionar em equilíbrio, aumentando, permanentemente, seu grau de organização interna e de adaptação ao meio.

Para construir esse conhecimento, as concepções infantis combinam-se às informações advindas do meio, na medida em que o conhecimento não é concebido apenas como sendo descoberto espontaneamente pela criança, nem transmitido de forma mecânica pelo meio exterior ou pelos adultos, mas, como resultado de uma interação, na qual o sujeito é sempre um elemento ativo, que procura ativamente compreender o mundo que o cerca, e que busca resolver as interrogações que esse mundo provoca.

b) O conteúdo das Representações Sociais de Ciência dos pais.

Para os pais utilizou-se o método interrogativo, com a seguinte pergunta: $O$ que é Ciência?

Dos vinte pais (10 pais e 10 mães) que participaram desta pesquisa emergiram 14 categorias, que revelam as ideias por eles manifestadas, representadas na Tabela 3.

Tabela 3 - Expressões relacionadas à Ciência e suas respectivas frequências aos vinte pais envolvidos na pesquisa. Obtidas através do método interrogativo.

\begin{tabular}{|l|l|l|}
\hline $\mathbf{N}^{\mathbf{o}}$ & Expressão & Freqüência \\
\hline 01 & Estudo do corpo & 06 \\
\hline 02 & Medicamentos & 05 \\
\hline 03 & Estudo das plantas & 04 \\
\hline 04 & Curar pessoas & 04 \\
\hline 05 & Alivia sofrimento & 03 \\
\hline 06 & Descoberta & 03 \\
\hline 07 & Invenções(televisão, rádio) & 04 \\
\hline 08 & Pesquisa & 03 \\
\hline 09 & Tratamento de doenças & 03 \\
\hline 10 & Experiência & 03 \\
\hline 11 & Vida & 03 \\
\hline 12 & Exames & 02 \\
\hline 13 & Estudo do ambiente & 02 \\
\hline 14 & Estudo & 01 \\
\hline
\end{tabular}

Aprofundando a leitura e análise dessas 14 expressões informadas, foi possível estabelecer 05(cinco) categorias, as quais foram agrupadas por expressões semelhantes ao que os pais concebem como Ciência. As cinco categorias estabelecidas, com suas respectivas frequências, estão na Tabela 4: 
Tabela 04 - Distribuição das Categorias e suas frequências.

\begin{tabular}{|l|l|l|}
\hline $\mathrm{N}^{\mathbf{o}}$ & Expressão & Freqüência \\
\hline 01 & Medicamentos & 17 \\
\hline 02 & Estudo & 13 \\
\hline 03 & Invenção/Descoberta & 07 \\
\hline 04 & Pesquisa & 06 \\
\hline 05 & Vida & 03 \\
\hline
\end{tabular}

A partir dos dados acima mencionados pode-se supor que para os pais, o núcleo duro da Representação Social sobre Ciência se caracteriza possivelmente por:

- medicamentos: que envolvem a cura, aliviam o sofrimento, tratam doenças;

- pesquisa, experiência, descobertas; é vida melhor;

- estudo: do corpo, das plantas, do meio ambiente.

Inferiu-se que para os pais a Ciência busca melhorar a qualidade de vida, fazendo com que as pessoas vivam mais tempo e com qualidade. Por isto, as expressões vida e estudo estão interligadas.

c) O conteúdo das Representações Sociais de Ciência das professoras.

Esta pesquisa buscou, além do conhecimento dos conteúdos da representação, conhecer também a sua estrutura ou organização interna. Para que isso se tornasse possível foi estabelecido um conjunto de técnicas adicionais, fundamentadas no princípio de se fazer com que o sujeito efetue sobre sua própria produção um trabalho cognitivo de análise, comparação e de hierarquização (Sá, 1998).

Aplicou-se um questionário em que foram solicitados alguns dados pessoais: há quanto tempo leciona, há quanto tempo está atuando nesta escola pesquisada, em que turma já atuou como docente nesta escola, se possui graduação, em que área. Depois utilizou-se a associação livre. Solicitando seis palavras que definissem Ciência, em seguida escolher dentre as seis, três que fossem mais significativas para a concepção de Ciência pelos educadores. Com as três palavras escolhidas explicar a importância de cada uma. E na última questão foi pedido que escrevessem como trabalham Ciência com os alunos durante as aulas e quando. Os resultados do questionário e da associação livre são apresentados nas tabelas 5,6 e 7.

Tabela 5 - Resultados do questionário

\begin{tabular}{|l|l|l|l|l|}
\hline & $\begin{array}{l}\text { Há quanto tempo } \\
\text { no Magistério? }\end{array}$ & $\begin{array}{l}\text { Há quanto tempo } \\
\text { lecionas } \\
\text { escola? }\end{array}$ & $\begin{array}{l}\text { Em que turmas já } \\
\text { atuaste nesta escola? }\end{array}$ & Possui Graduação? Qual? \\
\hline $\begin{array}{l}\text { Professora } \\
\text { A }\end{array}$ & 22 anos & 10 anos & $3^{\text {a }}$ série & Sim, Matemática. \\
\hline Professora B & 07 anos & 07 anos & $2^{\text {a }}$ e $3^{\text {a }}$ série & Sim, Letras Português / Inglês. \\
\hline Professora C & 29 anos & 04 anos & $1^{\text {a }}, 2^{\text {a }}$ e $4^{\text {a }}$ séries. & Sim, Pedagogia. \\
\hline $\begin{array}{l}\text { Professora } \\
\text { D }\end{array}$ & 29 anos & 29 anos & $\begin{array}{l}\text { Pré-escola, } 1^{\text {a }} \text { e } 2^{\text {a }} \\
\text { séries. }\end{array}$ & Sim, Pedagogia. \\
\hline
\end{tabular}


Tabela 6 - Expressões relacionadas à Ciência e suas respectivas frequências apresentadas pelas quatro professoras envolvidas na pesquisa

\begin{tabular}{|l|l|c|}
\hline $\mathrm{N}^{\mathbf{o}}$ & Expressão & Frequência \\
\hline 01 & Vida & 04 \\
\hline 02 & Água & 02 \\
\hline 03 & Meio Ambiente & 02 \\
\hline 04 & Natureza & 02 \\
\hline 05 & Ecologia & 01 \\
\hline 06 & Preservação & 01 \\
\hline 07 & Sustentabilidade & 01 \\
\hline 08 & Alimentação & 01 \\
\hline 09 & Saúde & 01 \\
\hline 10 & Animais & 01 \\
\hline 11 & Seres humanos & 01 \\
\hline 12 & Meio ambiente & 01 \\
\hline 13 & Ar & 01 \\
\hline 14 & Plantas & 01 \\
\hline 15 & Planetas & 01 \\
\hline 16 & Conhecimento & 01 \\
\hline 17 & Estudo & 01 \\
\hline 18 & Sobrevivência & 01 \\
\hline
\end{tabular}

Tabela 7 - Redefinindo Ciência com três palavras mais importantes para as professoras.

\begin{tabular}{|l|l|c|}
\hline $\mathrm{N}^{\mathbf{0}}$ & Expressão & Frequência \\
\hline 01 & Vida & 04 \\
\hline 02 & Meio ambiente & 02 \\
\hline 03 & Sustentabilidade & 01 \\
\hline 04 & Preservação & 01 \\
\hline 05 & Saúde & 01 \\
\hline 06 & Natureza & 01 \\
\hline 07 & Água & 01 \\
\hline 08 & Conhecimento & 01 \\
\hline
\end{tabular}

Aprofundando a leitura e análise dessas 08 expressões informadas, foi possível estabelecer 04(quatro) categorias, as quais foram agrupadas por expressões semelhantes ao que as professoras concebem como Ciência. As quatro categorias estabelecidas, com suas respectivas frequências, estão representadas na Tabela 8:

Tabela 8 - Distribuição das categorias e suas freqüências:

\begin{tabular}{|l|l|l|}
\hline Tema & Expressão & Frequência \\
\hline 01 & Vida & 05 \\
\hline 02 & Meio Ambiente & 04 \\
\hline 03 & Sustentabilidade & 02 \\
\hline 04 & Conhecimento & 01 \\
\hline
\end{tabular}


A partir dos dados acima mencionados pode-se supor que para as professoras, o núcleo duro da Representação Social sobre Ciência se caracteriza possivelmente por: vida, o meio ambiente, sustentabilidade e conhecimento.

Por tudo isto, o momento atual exige uma profunda reflexão sobre o Ensino de Ciências nas Séries Iniciais do Ensino Fundamental, ambiente que favorece a busca, o gosto por aprender, descobrir e reconstruir conhecimentos. Mas o docente continua tendo que dar conta de todas as áreas do conhecimento (Português, Matemática, História, Geografia, Ensino Religioso, Artes, Educação Física e Ciências), porém sabese que o enfoque sempre é maior para o Português e a Matemática. Por quê? Quais argumentos são utilizados pelos professores para darem mais ênfase a estes componentes curriculares? Acreditamos que estes são aspectos históricos que perpassam gerações, mas o presente estudo tem a intenção de valorizar mais o Ensino de Ciências nas séries Iniciais do Ensino Fundamental por acreditar que as formulações de conceitos e de atitudes podem e devem ser trabalhadas com os alunos desta faixa etária, pois os mesmos estão sedentos de saber, "o porquê das coisas" e os professores muitas vezes por não saberem ou por acreditarem que eles são muito novos, não lhes oportunizam tais momentos.

Outro fator que é pertinente refletir aqui é o curso de graduação realizado pelo professor. Quais disciplinas são oferecidas para trabalhar Ciências? Geralmente são específicas na parte da Matemática e da Biologia, mas e a Química e Física onde ficam? Então, como os cursos de licenciatura podem auxiliar o educador para trabalhar Ciências em todos os cursos de formação de docentes?

As respostas dadas pelas professoras da escola envolvida na pesquisa, tecendo comentários sobre a realidade dos alunos que elas atendem, contribuem para essa reflexão

Lembrando a pergunta:

- Como você desenvolve o Ensino de Ciências com seus alunos? Quando?

\section{Professora A}

Trabalho vários conteúdos da série, com filmes, textos, construção de livros, passeios de observação, diálogos, pesquisa, entrevistas.Mas as atitudes são lembradas, praticamente todos os dias e em vários momentos: fechar a torneira; lixo no lugar; merenda (alimentação); banho, dentes (higiene); animais (respeito, higiene, cuidados).

\section{Professora B}

Trabalho bem pouco a respeito de Ciências, só quando o projeto dá abertura e o que se trabalha de "prache" é meio ambiente, hábitos de higiene, alimentação. Muitas vezes passo mais de uma semana sem lecionar Ciências

\section{Professora $\mathrm{C}$}

- Através de observações - relatos de experiências, resgate /busca de vivências cotidianas e passadas;

- orientações através de leituras /pesquisas sobre as mudanças, transformações que ocorrem tanto no corpo como na natureza, meio ambiente; 
- comparações;

- alertas sobre: cuidados /preservação / economia / desperdício / danos, que causamos ao meio onde estamos inseridos.

Professora D

Observando fatos que acontecem no nosso dia-a-dia e comentando. Chamando atenção, e tomando conhecimento sobre o que os alunos já sabem, em sua vivência. E trabalhando assuntos do livro, quando estes se referem ao que estamos comentando.

As respostas das professoras estão mais concentradas no que se refere às atitudes dos alunos para com o cuidado com a vida, a natureza, a higiene corporal e o convívio com outras pessoas. Isto fica evidente quando se observa o Plano de Estudo destas turmas.

Cabe lembrar aqui que a atuação docente, na perspectiva de Vygotsky (1991), se dá na zona de desenvolvimento proximal do aluno, que é potencializada através da interação social, ou seja, as habilidades podem ser desenvolvidas com a ajuda de um adulto servindo de apoio ou através da colaboração entre pares. É na zona de desenvolvimento proximal, que acontecem as interações, para a construção do conhecimento ou da aprendizagem. Sendo, portanto, dinâmica e em constante mudança.

A função do professor é a de orientar de forma ativa e servir de guia para o aluno, de forma a oferecer apoio cognitivo. O professor deve ser capaz de ajudá-lo a entender um determinado assunto e, ao mesmo tempo, relacioná-lo ao conteúdo com experiências pessoais e o contexto no qual o conhecimento será aplicado. Ele ou ela deve também interferir na zona de desenvolvimento proximal de cada aluno, provocando avanços não ocorridos espontaneamente por este aluno. Várias atividades oferecidas devem ser flexíveis, permitindo ajustes no plano de aula. A intervenção por parte do professor é fundamental para o desenvolvimento do aluno. Deve intervir, questionando as respostas do aluno, para observar como a interferência de outro sujeito atinge no seu desenvolvimento e observar os processos psicológicos em transformação e não apenas os resultados do desempenho do aluno.

Contudo, essa intervenção no Ensino de Ciências é permeada pela débil formação em ciências, pelas representações sociais e pelas concepções pessoais do docente sobre o que é ensinar Ciências.

Ademais, Ausubel, em sua teoria (1968) se baseia no conhecimento prévio, aquilo que o aluno já sabe ou trás na bagagem de conhecimentos adquiridos, anteriormente à data em que o ensino aprendizagem está acontecendo. Sua teoria é construtivista e o papel da interação professor aluno, sem dúvida é importante, para, a partir dos subsunçores que o aluno possui construir novos subsunçores ou modificar os velhos. A aprendizagem em sala de aula deve ser dinâmica, deve resultar de uma interação entre aluno, professor, e materiais educativos partir do conhecimento prévio que o aluno tem.

Ausubel preocupa-se com a aprendizagem que ocorre na sala de aula da escola. Para ele fator mais importante de aprendizagem é o que o aluno já sabe. Para que ocorra a aprendizagem significativa conceitos relevantes e inclusivos devem estar claros e disponíveis na estrutura cognitiva do indivíduo, funcionando como ponto de ancoragem. 
No entanto, nem sempre isso ocorre e os conhecimentos disponíveis podem ser as conhecidas concepções alternativas ou representações sociais, objeto deste estudo. $\mathrm{Ou}$ seja, o conhecimento prévio é a variável mais importante para novas aprendizagens, mas esse conhecimento pode também influenciar negativamente a aprendizagem e até mesmo funcionar como obstáculo epistemológico.

O momento de aquisição de conhecimentos deve ser ativo, quanto mais ativo for este processo, mais significativos e úteis serão os conceitos, logo averiguar a Representação Social sobre Ciências para alunos, pais e docentes beneficiará o trabalho diário em sala de aula, com vistas a torná-lo mais significativo para os envolvidos.

\section{Construindo a Representação Social de Ciência}

De acordo com Moscovici (1978) as Representações Sociais são, ao mesmo tempo, um "produto" do social e um "processo" de instituição desse social, tendo entre outras, as funções de elaboração de determinar comportamentos e de comunicação entre indivíduos. Enquanto produto, Moscovici (1978) observou que as Representações Sociais se revelam em três dimensões, apresentadas pelos sujeitos, que permitem apreender o conteúdo delas e seu sentido sobre um determinado objeto, a saber: (a) nas atitudes; (b) nas informações; e (c) no campo de representação.

Assim sendo, a análise feita permitiu a identificação de uma parte desse processo de construção, que demonstra as categorias estabelecidas e seus sentidos, ou seja, aqueles que mais se destacaram em cada categoria. Nessa situação, as categorias correspondem à imagem, ou seja, a objetivação, elaborada pelos sujeitos em relação ao objeto, no caso a Ciência, e os significados representam os sentidos a ele atribuídos, ou seja, a ancoragem.

Portanto é possível supor que a Representação Social de Ciência evidenciada nesta pesquisa está vinculada ao estudo e à valorização da vida. Pois analisando os conteúdos apresentados pelos alunos, pais e professoras, percebe-se a importância da Ciência como estudo, conhecimento e descoberta que valorizam a qualidade de vida das pessoas. Pode-se concluir que estas foram as semelhanças apresentadas pelos grupos investigados. E isto confirma a hipótese de que a Representação Social de Ciência pode e deve servir como subsunçor, mas pode também funcionar como obstáculo epistemológico nas escolas, dificultando uma reestruturação curricular e atitudinal por parte dos alunos, pais e professores.

\section{CONSIDERAÇÕES FINAIS}

A análise dos resultados da pesquisa realizada junto aos alunos, pais e professoras desta Escola Estadual, buscou averiguar a Representação Social da Ciência. Assim como analisar os conteúdos de cada série, a maneira como eles são trabalhados em sala de aula e o que da bagagem de cada indivíduo é usado ou não no seu dia-a-dia e se a escola tem alguma influência nesta construção. 
Reafirmando Bizzo (2007, p. 07) “vivemos um momento de revisão de educação escolar, de seu papel e seu alcance. Juntamente com isso, vem o desafio da construção de um perfil profissional para o professor com base no seu trabalho em sala de aula, mas que se amplia para o desenvolvimento do projeto educativo da escola, para a produção, sistematização e socialização de conhecimentos pedagógicos e para a participação em discussões da comunidade educacional”.

É esta busca entre os saberes que precisam ser explorados na escola, ou seja, tornar o ensino mais real, frente aos problemas enfrentados diariamente e que estão vinculados aos saberes das Ciências. Por isto a afirmação de "modificar a preparação das aulas, proporcionar momentos de auto-reflexão aos estudantes, oferecer oportunidades para testar explicações e refletir sobre sua propriedade, limites e possibilidades são atividades que ensejarão uma forma muito diferente de ensinar $e$ aprender ciências. Essa nova forma de ensinar ciências demanda mudanças difíceis de serem realizadas, mas que certamente valerão à pena”. (Bizzo, 2007, p.137).

Além disto, "quando estudamos representações sociais nós estudamos o ser humano, enquanto ele faz perguntas e procura respostas ou pensa e não enquanto ele processa informação, ou se comporta. Mais precisamente, enquanto seu objetivo não é comportar-se, mas compreender". (Moscovici, 2007, p.43). Por isto a importância deste tipo de pesquisa para que o ser humano compreenda e reflita sobre a construção de seu conhecimento.

Por isto, para Guareschi (1995, p.149) "o conceito de representação social é multifacetado. De um lado, a representação social é concebida como um processo social que envolve comunicação e discurso, ao longo do qual significados e objetos sociais são construídos e elaborados. Por outro lado, e principalmente no que se relaciona ao conteúdo de pesquisas orientadas empiricamente, as representações sociais são operacionalizadas como atributos individuais - como estruturas individuais de conhecimento, símbolos e afetos distribuídos entre as pessoas em grupos ou sociedades. Esta dupla visão do conceito o faz versátil, e dá origem a várias interpretações e usos que nem sempre são compatíveis uns com os outros".

A partir deste estudo preliminar sobre a Representação Social de Ciências nas séries iniciais do Ensino Fundamental, nos pertimitimos sugerir que o objeto de estudo apresenta condições necessárias para emergir. Por isto para dar continuidade à pesquisa é preciso selecionar uma amostra de indivíduos que abranjam mais instituições de ensino e utilizar técnicas de coleta e análise de dados que sejam capazes de caracterizar melhor a estrutura (núcleo central e periférico) da possível Representação Social entre alunos, pais e professores, e a partir disto propor uma reformulação do Ensino de Ciências, de modo a promover uma mudança representacional.

\section{REFERÊNCIAS BIBLIOGRÁFICAS:}

Abric, J.C. (2001), Prácticas sociales y representaciones. México: Ediciones Coyoacán. Tradução do original Pratiques sociales et représentations. Paris: Presses Universitaires de France.

Ausubel, D. (1978). In defense of advance organizers: A reply to the critics. Review of Educational Research, 48, 251-257.

Bardin, L. (1979) Análise de conteúdo. Lisboa, Edições 70.

Bizzo, N. (2007) Ciências: fácil ou difícil? Editora: Ática, SP. 
Carvalho, A. M. P. Pérez, D. (2000).Formação de professores de ciências. São Paulo: Cortez.

Delizoicov, D. (org.); Angotti, J. A.; Pernambuco, M. M. (2002). Ensino de ciências: fundamentos e métodos. São Paulo: Cortez.

Fracalanza, H.; Amaral, I. A. do; Gouveia, M. S. F. (1986). O ensino de ciências no primeiro grau. São Paulo: Atual.

Freire, P. (1996). Pedagogia da autonomia: saberes necessários à prática educativa. São Paulo: Paz e Terra.

Guareschi, P. A, Jovchelovitch S. (1995). Textos em Representações Sociais. $2^{a}$ ed., Petrópolis, RJ: Vozes.

Jodelet, D.(1985). La representación social: Fenómenos, concepto y teoría. In: Psicologia Social (S. Moscovici, org.), pp. 469-494, Barcelona: Paídos.

Jodelet, D. $\left(1989^{\mathrm{a}}\right)$. Représentations sociales: un do-main en expansion. In: Les Représentations Sociales (D. Jodelet, org.), pp. 31-61, Paris: Presses Universitaires de France.

Lakatos, I. (1993) "La metodología dos Programas de investigação científica". Alianza. Madrid. Pág. 161.

Minayo, M. C. De S. (Org.) (1994). Pesquisa social: teoria, método e criatividade. Petrópolis, RJ: Vozes.

Morin E. (1983). O Problema Epistemológico da Complexidade. Lisboa: EuropaAmérica.

Morin, E. (1984). Idéias Contemporâneas - Entrevistas do Le Monde. São Paulo: Ática. Moscovici, S. A (1978). Representação Social da Psicanálise. Rio de Janeiro: Zahar.

Moscovici, S.A. (1988). Notes towards a description of social representations. European Journal of Social Psychology, 18: 211-250.

Moscovici, Serge, (2007). Representações Sociais: investigações em psicologia social. Petrópolis, RJ: Vozes.

Nascimento, I. P. (2002) As Representações Sociais do Projeto de Vida dos Adolescentes: um estudo psicossocial. S. Paulo, 209 p. Tese de Doutorado em Psicologia da Educação. Pontifícia Universidade Católica de São Paulo.

Perrenoud, P. (2000). Pedagogia diferenciada: das intenções à ação. Porto Alegre: Artes Médicas Sul.

Piaget, J. (1979). O Nascimento da Inteligência na Criança. Rio de Janeiro, Zahar.

Rampazzo, L. (2002) Metodologia Científica: para alunos dos cursos de graduação e pós-graduação. S. Paulo: Loyola.

Sá, C. P. de.,(1998) A construção do objeto de pesquisa em representações sociais. Rio de Janeiro: EDUERJ.

,(1996) Núcleo central das representações sociais. Petrópolis: Vozes.

Santos, W. L. P. dos; Schenetzler, R. P. (1997). Educação em química: compromisso com a cidadania. Ijuí: Ed. Unijuí,.

Vergs, P. (1992). L'evocation de l'argent: une méthode pour la definition du nayau central dune représentation. Paris: Bulletin de Psychologie, n. 45.

Vygotsky, L. (1991). Pensamento e linguagem. 3.ed. São Paulo: M. Fontes.

Weissmann, H. (1998) O laboratório escolar. In: Weissmann, H (org.) Didática das Ciências Naturais: contribuições e reflexões, Porto Alegre: ArtMed. 